\title{
UMA REVISÃO SOBRE A ECONOMIA BRASILEIRA E O MERCADO FINANCEIRO APÓS O PLANO REAL: As mudanças e a evolução do mercado de capitais entre 1995 e 2002
}

\author{
Valdir de Jesus Lameira \\ Doutorando em Administração - PUC - RJ \\ Mestre em Engenharia de Produção - UFF - RJ \\ E-mail: vlameira@uol.com.br
}

\section{RESUMO}

É amplamente conhecida a importância para a economia de qualquer país, da existência de um sistema financeiro que atue com eficiência na gestão dos riscos e na alocação dos recursos e que tenha um alto grau de confiabilidade (ROCCA, 2001).

O Plano Real, iniciado em meados de 1994, proporcionou o controle da inflação em nossa economia através de mecanismos que permitiram uma ampla abertura ao comércio exterior, da mesma forma como aumentou a integração de nosso sistema financeiro aos mercados financeiros internacionais. Desse modo, o Plano Real provocou intensas modificações em nosso sistema financeiro.

O objetivo deste trabalho é fornecer uma visão do ambiente econômico brasileiro e um panorama sobre os principais eventos ocorridos no mercado financeiro e de capitais brasileiro após o início do Plano Real, no período compreendido entre 1995 e 2002. A esse respeito, será verificada a evolução das principais variáveis macroeconômicas, a nova estruturação do sistema financeiro, o ingresso de novos agentes internacionais, a evolução dos negócios no mercado de capitais e também o comportamento das finanças governamentais.

Por último, será possível perceberem-se as melhorias qualitativas ocorridas no período e a necessidade de se promoverem ajustes importantes tanto na administração das contas públicas como no aumento da poupança interna e, conseqüentemente, no nível de investimentos em nossa economia.

Palavras-chave: Sistema financeiro, Mercado financeiro e Mercado de capitais.

\section{ABSTRACT}

Everybody knows the importance of an efficient financial market with efficient risk management and resource allocation and also with a great confidence level for the economy of any country. (Rocca, 2001)

The Brazilian stabilization plan, called Plano Real, which started in the middle of 1994, made it possible to control inflation in the Brazilian economy by mechanisms that allowed for a greater opening to foreign trade and increased the integration between the Brazilian financial system and international financial markets. Hence, the Plano Real provoked intense changes in our financial system.

This article aims to offer a view on the Brazilian economic environment and show the most important events in the Brazilian financial and capital market after the advent of the monetary stabilization program, during the period between 1995 and 2002. W observe the evolution of the main macroeconomic variables, the new structure of the financial system, the entrance of new international agents, the evolution of the capital market business and the behavior of public finances.

Finally, we will demonstrate the qualitative improvements that occurred during the period and the need for important adjustments in public account management as well as in the increase of internal savings and, consequently, the level of investments in the Brazilian economy.

Keywords: Financial system, Financial market, Capital market. 


\section{INTRODUÇÃO: UMA VISÃO DA GLOBALIZAÇÃO DOS MERCADOS}

No passado, os bancos operavam em qualquer mercado financeiro com boas margens de lucros, previamente definidas, em um ambiente de relativa estabilidade nos meios econômico e financeiro, menores riscos de perdas nos financiamentos e pequenos riscos de perdas de investidores em vista da pequena gama de produtos no mercado financeiro (LAMEIRA, 2001).

No presente cenário, vigora a desregulamentação das comissões bancárias, a negociação direta entre clientes e bancos por melhores condições contratuais e por produtos que melhor se adeqüem às necessidades das empresas (LAMEIRA, 2001).

Dessa forma, nos países com mercado de capitais desenvolvidos, os bancos se tornam participantes ativos desse mercado e sua função de intermediário financeiro entre poupadores e demandantes de recursos coexiste ao lado da função de administrador de recursos e gerenciador de riscos relativos a ativos próprios e de terceiros (LAMEIRA, 2001).

Assim sendo, em média no ano de 2000 apenas $40 \%$ dos lucros bancários americanos derivaram da concessão de crédito. $O$ restante foi proveniente da administração de recursos. Essa situação provocou um aumento do nível de risco das instituições e, em conseqüência, do sistema financeiro, por duas razões:

- Os bancos trabalhavam com recursos ao mesmo tempo voláteis e mais sensíveis ao risco;

- Em 1978, 21\% dos ativos bancários eram financiados por recursos de grandes companhias e investidores. Em 2000, 36\% dos ativos eram financiados por dinheiro captado junto ao mercado. Da mesma forma, em 1996, os depósitos em conta ou similares financiavam $54 \%$ dos ativos bancários, sendo que, no último trimestre do ano de 2.000 , isso representava apenas $45 \%$ do total desses ativos. Portanto, pode-se concluir que os bancos estão assumindo um risco de descasamento de prazos cada vez mais elevado e, muitas vezes, administrando esse risco através de operações com derivativos, conforme a referência.

Ainda a respeito dos mercados financeiros desenvolvidos, percebeu-se ao longo dos últimos anos uma diminuição dos serviços oferecidos pelas instituições bancárias em vista do crescimento dos fundos mútuos de investimento e também pelo aumento da demanda pelo mercado de capitais por parte das empresas americanas em especial (ALMEIDA, 1997). Além disso, ocorreu uma brutal redução no número de instituições financeiras bancárias nos EUA e nas principais economias da Europa e da Ásia. Desde o ano de 1980, mais de 6000 bancos foram incorporados por meio de processos de fusão somente nos EUA (ALMEIDA, 2000).

Foi nesse cenário que se verificou a desregulamentação dos negócios financeiros americanos acontecida ao longo dos anos 80 e 90 e que influenciou, significativamente, a integração dos sistemas financeiros pelo mundo. O processo envolveu a integração desses sistemas financeiros no mundo global de negócios e conseqüente crescimento de mercados financeiros secundários em economias emergentes, fato que tornou possível um aumento significativo de oportunidades de investimento, de operações de arbitragem e de movimentos especulativos (ALMEIDA, 2000).

Assim é que a globalização dos mercados financeiros foi marcada pela quase completa integração entre os movimentos de capitais pelas economias vis-à-vis a avaliação constante dos fatos relevantes e das condições econômicas e financeiras de diversos países, suas moedas, suas taxas de câmbio e suas taxas internas de juros. Essa observação pode ser confirmada especialmente pelos impactos globais que as crises nos países emergentes suscitaram (PINHEIRO, 2000).

Logo, observou-se a criação de um fluxo permanente de capitais procurando as melhores opções de retorno e risco pelo mundo bem como aumentaram a volatilidade e risco envolvido nos mercados financeiros (CINTRA, 1998).

A integração dos sistemas financeiros apresentava como expectativa o aumento da eficiência de alocação de recursos nas economias dos países emergentes em vista do ingresso de grandes instituições financeiras globais em condições de fomentar os mercados de crédito dessas economias a partir da melhoria das condições a serem oferecidas, quer seja por meio da oferta de maiores volumes, de melhores taxas ou de prazos, condições possíveis de serem conseguidas nos mercados financeiros internacionais (ALMEIDA, 1997). 
Essa seria a principal contribuição da integração dos sistemas financeiros pois se sabe que, em economias em que persistem problemas inerentes ao desenvolvimento econômico que afetam o desenvolvimento dos mercados de capitais, o mercado de crédito assume vital importância para o fornecimento de crédito às empresas (LAMEIRA, 2001).

É, dessa forma, que, nas economias emergentes, os bancos comerciais representavam e representam a principal fonte de recursos para as empresas e operam com diferenças expressivas de taxas (spread) (ALMEIDA, 1997). Nas Tabelas 1 e 2, podem ser verificados, respectivamente, os valores médios das taxas das operações ativas e passivas além dos percentuais médios anuais de spread praticados em nossa economia nos anos de 97 a 99 e, na Tabela 2, os valores de spreads médios dos últimos anos que comprovam a afirmação anterior.

\section{Tabela 1 - Taxas das operações ativas e passivas e percentuais médios anuais de spreads no setor de crédito}

\begin{tabular}{c|c|c|c|c|c|c|c|c|c|c|c|}
\hline & Oper. & \multicolumn{3}{c|}{ Oper. } & \multicolumn{2}{c|}{ Passivas } & \multicolumn{2}{l}{ Spread } \\
\cline { 2 - 9 } & 1997 & 1998 & $1999\left(^{*}\right)$ & 1997 & 1998 & $1999\left(^{*}\right)$ & 1997 & 1998 & $1999\left(^{*}\right)$ \\
\hline Brasil & 61,59 & 64,86 & 54,24 & 24,34 & 28,00 & 19,14 & 37,25 & 36,86 & 35,10 \\
\hline
\end{tabular}

Fonte: Relatório Econômico da Andima - Sistema Financeiro no Mercosul dezembro/99 - (*) até setembro.

Tabela 2 - Percentuais médios anuais de spreads brutos do setor de crédito

\begin{tabular}{l|l|l|l|l|l|l|c|} 
& 1997 & 1998 & 1999 & 2000 & 2001 & 2002 & $2003\left(^{*}\right)$ \\
\hline Spreads & 37,25 & 36,86 & 35,10 & 27,23 & 26,97 & 29,99 & 32,37 \\
\hline
\end{tabular}

Fonte: Relatório da Andima e Banco Central - $\left(^{*}\right)$ até setembro.

Contudo, apesar de se saber que a intermediação financeira e uma "cultura de crédito" são condições indispensáveis para o desenvolvimento econômico sustentado, no Brasil prevaleceu, por décadas, a poupança forçada, de financiamento inflacionário, de créditos subsidiados via instituições financeiras públicas e de investimento de empresas públicas e do gasto público como os verdadeiros motores de investimento (MALAN, 2000).

Além disso, a despeito de todas as vantagens previamente esperadas, a integração dos mercados financeiros apresentou alguns problemas. Verificouse, ao longo do tempo, a vulnerabilidade dos sistemas de controle de riscos evidenciados pelas crises russa, asiática e mexicana. Foram exemplos dessa vulnerabilidade a incapacidade das grandes instituições de diminuírem sua exposição ao risco em momentos de crises muito disseminadas; a dificuldade de se encontrarem ativos em proporção suficiente para se evitarem grandes perdas por parte das grandes instituições; e o crescimento exagerado da volatilidade por períodos mais longos que os sugeridos pelas expectativas geradas pelos modelos de estudos (ALMEIDA, 2000).
Assim sendo, verificar-se-à, a seguir, como esse macro ambiente global impactou em nosso mercado financeiro e em suas deficiências, além de promover-se uma síntese dos fatos mais relevantes e uma revisão da evolução do ambiente econômico e financeiro nacional no período sugerido para estudo.

\section{A EVOLUÇÃO ECONÔMICA APÓS O PLANO REAL}

O Plano Real surgiu em um ambiente econômico mundial de elevada liquidez nos mercados financeiros desenvolvidos (ANDREZO, 1999), provocada pelo alto crescimento da economia americana, pela grande geração de riqueza nos seus mercados de capitais e em decorrência de um grande volume de comércio mundial.

Internamente, o plano de estabilização pretendia controlar a inflação mediante a liberação de nossa economia ao comércio mundial, especialmente às importações, com uma taxa de câmbio que apresentava elevada apreciação de nossa moeda frente ao dólar americano (ANDREZO, 1999). As importações atendiam à demanda derivada do crescimento da 
renda que havia sido provocado pela queda da inflação. A Tabela 3 ilustra a evolução do Índice Geral de Preços de Mercado (calculado pela Fundação Getúlio Vargas) no período compreendido entre 1989 e 1993 e entre 1994 e 2003, que permite sejam com- parados os valores nos períodos e verificado o êxito no controle da variação de preços, exceções feitas à crise cambial ocorrida ao final de 1998 com efeitos em 1999 e a crise ocorrida às vésperas da eleição de 2002 com reflexos também em 2003.

Tabela 3 - IGPM (Índice Geral de Preços de Mercado) - Valores extremos de taxas do IGPM mensal (\%)

\begin{tabular}{|c|c|c|}
\hline & Valores mínimos & Valores máximos \\
\hline 1989 & 19,68 & 47,13 \\
\hline 1990 & 5,93 & 83,95 \\
\hline 1991 & 7,48 & 25,62 \\
\hline 1992 & 19,94 & 26,76 \\
\hline 1993 & 25,83 & 38,32 \\
\hline 1995 & $-0,71$ & 2,46 \\
\hline 1996 & 0,10 & 1,73 \\
\hline 1997 & 0,09 & 1,77 \\
\hline 1998 & $-0,17$ & 0,45 \\
\hline 1999 & $-0,29$ & 3,61 \\
\hline 2000 & 0,15 & 2,39 \\
\hline 2002 & 0,06 & 5,19 \\
\hline 2003 (até out.) & $-0,42$ & 2,33 \\
\hline
\end{tabular}

Fonte: Banco Central $\left(^{*}\right)$ Junho foi o mês de início do Plano Real.

Esse mecanismo de estabilização denominado âncora cambial gerava um elevado déficit em conta corrente (transações do país com o exterior) que seriam financiados pelo ingresso de capitais estrangeiros na forma de investimentos diretos e de investimentos estrangeiros de curto prazo que se aproveitavam de nossa altas taxas internas de juros (ANDIMA, 1999).

Dessa forma, convivia-se com uma boa liquidez no sistema financeiro nacional (devido ao excesso de dólares aportados no país) sustentado pelo ambiente externo com grande oferta de recursos. Para diminuir a liquidez observada na economia a autoridade monetária colocava em prática altas taxas internas de juros. Contudo, a oferta de recursos e a demanda crescente, em vista da queda da inflação, preponderou e proporcionou, durante os primeiros três anos do referido período (95 a 98), o controle da inflação medida por nossos níveis gerais de preços e um crescimento econômico de 4,2\% em 1995, de $2,7 \%$ em 1996 e de $3,3 \%$ em 1997, medidos como percentuais de crescimento do PIB.

A utilização de uma política monetária extremamente contracionista (de juros elevados) fez com que as taxas internas de juros atingissem níveis punitivos para os agentes econômicos que pretendessem especular com formação de estoques e posterior elevação de preços, elevando o custo de oportunidade desses agentes. Contudo, essas taxas, também, elevaram sobremaneira o custo de capital e terminaram por comprimir a demanda agregada e o nível de investimentos além de manter totalmente atrofiado o nível de crédito em nossa economia em vista dos elevados juros nominais e reais praticados, estes últimos possíveis de serem verificados a partir dos dados das seguintes Tabelas 4 e 5 . 
Tabela 4 - Taxas médias finais de empréstimo concedidas pelos sistemas financeiros

\begin{tabular}{c|c|c|c|c|c|c} 
& $\begin{array}{c}\text { Taxa Selic média } \\
\text { do ano }\end{array}$ & $\begin{array}{c}\text { Spread Bruto } \\
\text { médio anual }\end{array}$ & $\begin{array}{c}\text { Taxa mínima de } \\
\text { empréstimo no Brasil }\end{array}$ & $\begin{array}{c}\text { Taxa final } \\
\text { EUA }\left(^{*}\right)\end{array}$ & $\begin{array}{c}\text { Taxa final } \\
\text { Japão }\left(^{*}\right)\end{array}$ & $\begin{array}{c}\text { Taxa final } \\
\text { Alemanha }\left(^{*}\right)\end{array}$ \\
\hline 1995 & 55,09 & n.d. & n.d. & 8,50 & 4,05 & 11,27 \\
\hline 1996 & 27,60 & n.d. & n.d. & 8,50 & 8,25 & 10,39 \\
\hline 1997 & 25,17 & 37,25 & 62,42 & 8,50 & 2,53 & 9,26 \\
\hline 1998 & 29,51 & 36,86 & 66,37 & 7,75 & 2,37 & 9,05 \\
\hline 1999 & 26,26 & 35,10 & 61,32 & 8,50 & 2,09 & 8,87 \\
\hline 2000 & 17,59 & 27,23 & 44,82 & 9,05 & 2,11 & 1,97 \\
\hline 2001 & 17,47 & 26,97 & 44,44 & 4,75 & 1,88 & 9,39 \\
\hline 2002 & 19,11 & 29,99 & 49,10 & 4,25 & 1,84 & 9,58 \\
\hline 2003 & 20,42 & 32,37 & 52,79 & & 9,68 \\
\hline
\end{tabular}

Fonte: Banco Central $\left(^{*}\right)$ valores do mês de janeiro.

Tabela 5 -- Crédito concedido pelo sistema financeiro no Brasil (Bilhões de Reais)

\begin{tabular}{c|cc}
\hline & Total de crédito interno & Total concedido ao setor privado (*) \\
\hline 1995 & 256 & 226 \\
\hline 1996 & 318 & 236 \\
\hline 1997 & 378 & 311 \\
\hline 1998 & 513 & 331 \\
\hline 1999 & 508 & 381 \\
\hline 2000 & 545 & 410 \\
\hline 2002 & 701 & 468
\end{tabular}

Fonte: Banco Central $\left({ }^{*}\right)$ valores de dezembro desses anos não considerando a incorporação do valor da inflação verificada no decorrer dos anos.

Assim, como já foi comentado, observou-se um período de razoável crescimento econômico devido ao endividamento externo e aos investimentos diretos externos feitos em nosso setor produtivo e a um aumento de consumo ${ }^{1}$ provocado pela liquidez derivada da imensa quantidade de recursos externos que ingressavam em nossa economia, ainda que se pusesse em prática uma política de juros reais extremamente elevados (ANDREZO, 1999).

Esse excesso de dólares aportados em nossa economia e acumulados em Reservas Internacionais serviu de segurança contra eventuais ataques especulativos contra nossa moeda em momentos de crises financeiras pelo mundo. Contudo, os estoques de dívida contraída eram muito bem remunerados e geraram uma elevação brutal de nosso endividamento, conforme demonstra a Tabela 6.

Deve-se ressalvar que todos os "esqueletos" (dívidas originadas em governos anteriores e que não haviam sido contabilizadas até aquele momento) foram incluídos no estoque de dívida que foram mencionados anteriormente. No período atual, somente a dívida referente ao saldo negativo das operações relacionadas ao Fundo de Cobertura de Variações Salariais pode ser incluída como último esqueleto a ser incorporado à dívida da União.

${ }^{1}$ Segundo dados do IBMGE, o consumo, nos últimos anos, responde por cerca de $63 \%$ na formação do PIB brasileiro. 
Tabela 6 - Reservas Internacionais, Dívida Externa Bruta e Líquida (U\$ Milhões)

\begin{tabular}{|c|c|c|c|c|c|}
\hline & Reservas Internacionais & Divida Externa Bruta & Dívida Externa Liquida & PIB & Dívida Bruta/PIB (\%) \\
\hline 1994 & 38806 & 148295 & 94459 & 543086 & 27,30 \\
\hline 1995 & 51840 & 159258 & 92347 & 705449 & 22,58 \\
\hline 1996 & 60110 & 179934 & 100561 & 775474 & 23,20 \\
\hline 1997 & 52173 & 199997 & 130854 & 807814 & 24,76 \\
\hline 1998 & 44556 & 241644 & 182287 & 787889 & 30,67 \\
\hline 2000 & 33011 & 236156 & 190319 & 602206 & 39,22 \\
\hline 2001 & 25866 & 209934 & 162704 & 510359 & 41,13 \\
\hline 2002 & 37823 & 210711 & 165002 & 451005 & 46,72 \\
\hline
\end{tabular}

Fonte: Banco Central.

Assim, o plano de estabilização dentro dessa configuração promoveu a estabilidade de preços até o final do ano de 1998. Nesse ano, mesmo com o ingresso de um volume significativo de créditos aportados pelo Fundo Monetário Internacional, havia uma percepção de maior risco em nossa economia. A relação dívida/PIB se mostrava crescente e terminaria por deflagrar uma crise de financiamento, com fuga de recursos de nossa economia e conseqüente crise cambial ${ }^{2}$ pois o mercado passou a exigir maiores prêmios (remuneração), além de se observarem movimentos de corrida para compra de dólares como forma de proteção (hedge) para possíveis perdas de valor dos ativos.
Portanto, foi nesse contexto que as instituições financeiras começaram a demandar maior volume de dólares enfraquecendo nossas Reservas Internacionais (Banco Central, 1999), provocando perdas sucessivas de recursos que haviam ingressado em nossa economia. Essa era a sinalização de que o modelo de endividamento para a captação de recursos do exterior e a política de controle de taxas de câmbio por parte do Banco Central começava a se exaurir. Na Tabela 7, verifica-se a evolução do passivo externo bruto total do setor público e privado nacionais, que confirma a evolução da dívida externa brasileira.

Tabela 7 - Endividamento externo do Brasil no período 1995 a 2002

\begin{tabular}{|c|c|c|}
\hline & Passivo Externo Bruto Total (U\$ Bilhões) & Passivo Externo Bruto Privado (U\$ Bilhões) \\
\hline 1995 & 256,2 & 161,1 \\
\hline 1996 & 288,5 & 194,9 \\
\hline 1997 & 319,5 & 233,8 \\
\hline 1998 & 368,0 & 272,7 \\
\hline 1999 & 369,3 & 268,7 \\
\hline 2000 & 379,3 & 287,0 \\
\hline 2001 & 363,0 & 269,8 \\
\hline 2002 & 328,7 & 227,7 \\
\hline
\end{tabular}

Fonte: Banco Central.

Assim, a partir do ano de 1998, o governo resgatou a formação de taxas de câmbio flutuantes ajustadas aos movimentos do mercado financeiro nacional e internacional, bem como as taxas de juros retornaram a cumprir sua função de uma política monetária ativa para o controle dos níveis de preços praticados em nossa economia (ANDIMA, 1999).

Dessa forma, o governou passou a conduzir a economia de maneira diferente. Percebendo a exaustão da opção de crescimento da poupança via endividamento externo e observando o estreitamento 
da captação de investimentos diretos, o governo imprimiu uma reversão muito drástica de objetivos na política econômica no sentido de equilibrar as variáveis macroeconômicas atuando de modo a formar um grande superávit comercial (BANCO CENTRAL, 2002) com impulso no crescimento das exportações, conforme é mostrado na Tabela 8, a seguir.

Tabela 8 - Taxas de crescimento do passivo externo e exportações entre 1995 e 2002

\begin{tabular}{c|c|c|c} 
& & $\begin{array}{c}\text { Crescimento Médio do } \\
\text { Passivo Externo Bruto (\%) }\end{array}$ & $\begin{array}{c}\text { Crescimento Médio das } \\
\text { Exportações (\%) }\end{array}$ \\
\hline Entre 1995 e 1998 & Câmbio Fixo & $9,3 \%$ & $4,1 \%$ \\
\hline Entre 1999 e 2002 & Câmbio Flutuante & $-1,1 \%$ & $4,7 \%$ \\
\hline
\end{tabular}

Fonte: Banco Central.

Assim sendo, se por um lado a subida da taxa de câmbio se mostrou perversa pois resultou na formação de uma bolha inflacionária em 1999, devido ao fato de afetar diretamente a formação de diversos preços na economia brasileira, por outro lado incentivou, sobremaneira, o setor exportador nacional que gerou sucessivos superávits comerciais que possibilitaram uma sustentação na busca do equilíbrio das contas macroeconômicas do país (BANCO CENTRAL, 2002).

Esse era o cenário que se apresentava até às vésperas da eleição presidencial de 2002. Nesse momento, os administradores de recursos passaram a não aceitar a renovação de seus financiamentos do déficit público, senão atrelando os rendimentos dos títulos da dívida pública à variação cambial. Além disso, ocorreu um estreitamento do período de vencimento desses títulos, acima do que se poderia esperar mesmo em momento de expectativa de transição de poder. Some-se a isso o fato de que várias linhas de crédito de curto prazo fornecidas por instituições financeiras estrangeiras e vinculadas a operações de exportação de companhias brasileiras foram extintas. A visão de risco associada à possibilidade de vitória da oposição foi tecnicamente errônea e extremamente prejudicial ao país.

Portanto, para refinanciar a dívida pública a autoridade monetária promoveu uma emissão de títulos indexados à variação cambial (BANCO CENTRAL, 2002). Esse instrumento é salutar quando representa pequena parte do total da dívida emitida e em circulação e extremamente perigoso se provocar uma indexação de grande parte dessa dívida mobiliária.

A esse respeito, entende- $\mathrm{se}^{3}$ que ao se atrelar a dívida interna à variação do dólar ou de uma cesta de moedas com o propósito de se promover o equilíbrio das contas nacionais é necessário que se imprimam: aos ativos financiados níveis de remuneração econômicos e financeiros compatíveis com os observados em economias já desenvolvidas. Caso contrário pode-se observar uma grande incompatibilidade em se gerenciar, eficientemente, os passivos e ativos, em vista de suas diferentes expectativas de retornos e fluxos, o que pode provocar primeiro o colapso financeiro e depois o colapso econômico do país.

Dessa forma, conclui-se que o financiamento da geração do produto no país se deu, até 1999, pela capacidade de endividamento (limitada à percepção de risco e condições econômicas do financiador externo) e, a partir de 1999, passou a ser dependente da geração de superávits comerciais provenientes do setor externo.

Quanto ao nível de investimentos em nossa economia durante o período de 1995 até 2002, pode-se dizer que esse se manteve em nível insatisfatório para um processo de crescimento sustentado (abaixo de $25 \%$ ao ano) e com tendência decrescente nos últimos anos, em patamares em torno de $18 \%$ ao ano, especialmente após a crise cambial de $1999^{4}$.

Durante o período de 1994 até 2002, a formação bruta de capital fixo se situou na faixa de 19,10 a $19,45 \%$ do PIB tendo-se observado um crescimento

\footnotetext{
${ }^{3}$ Este raciocínio foi derivado da leitura da referência bibliográfica Macroeconomia de DORNBUSCH \& FISCHER.

${ }^{4}$ Segundo Renato Baumann no artigo "Exportações e capital estrangeiro: velhos temas em novo contexto" contido ?no livro Fórum Nacional Brasil 500 anos: passado, presente e futuro, estudo coordenado pela Cepal (MOGUILLANSKY/BIELSCHOWSKY - 2000) mostra que, na segunda metade dos anos 90 (95-98), a relação investimento/PIB no Brasil teve recuperação atingindo $16,8 \%$ comparado com os 14,6\% do período 90-93, porém muito aquém dos anos 70 quando o nível foi de $23,3 \%$.
} 
médio negativo do PIB da ordem de $0,26 \%$ ao ano, se avaliado em termos de dólares médios dos anos que compõem o período. Comparando os dados do período com os dados de períodos anteriores, como pode ser visto na Tabela 9, verifi- ca-se que, em termos de desenvolvimento, nossa economia patinou se for observado o crescimento do produto, porém, recuperou, em parte, condições para constatar-se algum crescimento do produto nos próximos anos.

Tabela 9 - Crescimento do PIB e formação bruta de capital fixo

\begin{tabular}{c|cc} 
& Crescimento do PIB & Formação Bruta de Capital Fixo \\
\hline Entre 1971 e 1982 & $6,4 \%$ & $21,6 \%$ \\
\hline Entre 1983 e 1988 & $3,4 \%$ & $17,2 \%$ \\
\hline Entre 1989 e 1994 & $1,1 \%$ & $14,8 \%$ \\
\hline Entre 1995 e 2001 & $-0,26 \%$ & $19,4 \%$
\end{tabular}

Fonte: IBGE.

Ao analisar-se a capacidade de formação de poupança pelo governo nos últimos anos (Tabela $10)$, verifica-se, também, que, apesar da recuperação apresentada nos últimos anos de 2000 e 2001, a média do período de 1995 até 2001 é a pior desde a década de 1970. A formação de poupança é, basicamente, obtida do setor privado mas, ainda, a níveis insuficientes para a necessidade de investimentos compatíveis com o que se almeja em termos de desenvolvimento econômico (ROCCA, 2001).

Tabela 10 - Poupança do governo

\begin{tabular}{l|c}
\hline & Poupança do Governo \\
\hline Entre 1970 e 1974 & $6,4 \%$ \\
\hline Entre 1975 e 1979 & $5,3 \%$ \\
\hline Entre 1980 e 1984 & $2,0 \%$ \\
\hline Entre 1985 e 1989 & $-1,2 \%$ \\
\hline Entre 1990 e 1994 & $-1,9 \%$ \\
\hline Entre 1995 e 2001 & $-11,4 \%$ \\
\hline
\end{tabular}

Fonte: IBGE.
Analisando as contas internas do governo de uma forma mais ampla, verifica-se que a busca do equilíbrio fiscal das contas públicas passa, necessariamente, pela correção estrutural da gestão das contas previdenciárias e pela diminuição dos juros e serviços da dívida a serem pagos. Para isso é necessário que o Estado diminua sua participação na atividade econômica delegando à iniciativa privada a função de fomentar o crescimento econômico (ROCCA, 2001).

$\mathrm{Na}$ forma atual, a necessidade de financiamento do Estado gira em torno de $4,40 \%$ do PIB como forma de manter suas atividades e sustentar o pagamento de seus encargos. Devido a essa situação deficitária, o governo, anualmente, capta recursos nos mercados monetário ou de crédito, dentro ou fora do país, provocando um círculo vicioso que impede a queda dos juros por não se vislumbrarem melhores expectativas em relação ao endividamento, em função da observação da constante demanda por recursos por parte do governo para financiar seus sucessivos déficits nos últimos anos, como se pode observar na Tabela 11.

Tabela 11 - Contas do governo (valores monetários em Bilhões de Reais)

\begin{tabular}{c|c|c|c|c|c} 
& $\begin{array}{c}\text { Poupança } \\
\text { Pública }\end{array}$ & $\begin{array}{c}\text { Prestação de } \\
\text { Serviços }\end{array}$ & $\begin{array}{c}\text { Previdência } \\
\text { Pública e Privada }\end{array}$ & Juros & $\begin{array}{c}\text { Necessidade de } \\
\text { Financiamento/PIB (\%) }\end{array}$ \\
\hline 1997 & -22 & 63 & -48 & -37 & 4,14 \\
\hline 1998 & -39 & 64 & -55 & -47 & 4,32 \\
\hline 1999 & -58 & 91 & -65 & -83 & 4,73 \\
\hline 2000 & -29 & 119 & -76 & -71 & 4,24 \\
\hline 2001 & -21 & 139 & -82 & -79 & 4,54 \\
\hline Média & -34 & 95 & -65 & -63 & 4,40 \\
\hline
\end{tabular}

Fonte: IBGE. 


\section{A EVOLUÇÃO DO SISTEMA FINANCEIRO NO PERÍODO}

Portanto, o fim da hiperinflação e as taxas mais civilizadas de inflação que marcaram a economia brasileira após o Plano Real exibiram com clareza certas fragilidades estruturais de intermediação financeira no Brasil, expondo a situação de um número não desprezível de bancos públicos e privados que só tinham condição de sobreviver no contexto de um processo inflacionário crônico que permitia que suas receitas inflacionárias chegassem, em alguns casos, a mais de um terço de suas receitas totais (MALAN, 2000).

Além dessa situação, alguns outros fatos foram marcantes ao longo desse período no ambiente financeiro nacional. Entre outros assuntos, podem ser mencionados o acréscimo de transparência da autoridade monetária, a excepcional concentração ocorrida no sistema financeiro com a diminuição muito grande do número de pequenas instituições ${ }^{5}$, a perda de especialização, o surgimento de grandes conglomerados financeiros e o aumento da fiscalização, principalmente em função de se evitar a lavagem de dinheiro (ANDIMA, 1999).

Ainda sobre o assunto, podem-se incluir: a criação da Central de Risco de Crédito no Banco Central para melhoria das avaliações de crédito (BANCO CENTRAL, 1997), a criação do Fundo Garantidor de Créditos para garantir parte dos créditos dos investidores (ANDREZO, 1999), entre outros.

É possível identificarem-se as mudanças do sistema financeiro enquadrando-as em três fases distintas. A $1^{\text {a }}$ fase seria a do início, em meados de 1994 até meados de 1996, com os seguintes fatos marcantes: fusões e aquisições entre as instituições financeiras privadas, aperfeiçoamento da regulação e supervisão do sistema e criação do $\operatorname{PROER}^{6}{ }^{7}$; a $2^{\mathrm{a}}$ fase seria de meados de 1996 até o final do ajustamento promovido pelo PROES $\left({ }^{*}\right)$ e o ingresso dos bancos estrangeiros ${ }^{8}$; a $3^{\mathrm{a}}$ fase seria a mudança da administração dos bancos (BARROS, 1998).

No âmbito do mercado de capitais, verificou-se a entrada de grandes volumes de recursos por parte dos investidores estrangeiros na forma de investimento diretos, o que inclusive, segundo a autoridade monetária, dificultava a administração da política monetária e fiscal (BANCO CENTRAL, 1996). O ingresso de recursos externos aumentou após a liberação do câmbio ocorrida ao final do ano de 1998 e declina em 2002 devido ao risco associado ao processo eleitoral. O objetivo principal desses investimentos era participar das privatizações ${ }^{9}$. O montante de recursos no tempo pode ser observado na Tabela 12, a seguir.

\section{Tabela 12 - Investimento Direto (U\$ Milhões)}

\begin{tabular}{c|c}
\hline & $\begin{array}{c}\text { Valor do Investimento } \\
\text { Direto Liquido }\end{array}$ \\
\hline 1994 & 1480 \\
\hline 1995 & 3309 \\
\hline 1996 & 11260 \\
\hline 1997 & 17877 \\
\hline 1998 & 26001 \\
\hline 1999 & 26888 \\
\hline 2000 & 30497 \\
\hline 2001 & 24714 \\
\hline 2002 & 14084
\end{tabular}

Fonte: Banco Central.

A respeito dos investimentos estrangeiros em carteira, observa-se que, até a crise cambial de 1998, o saldo dos investimentos era extremamente positivo. A partir de 1998, começou a se perceberem saldos líquidos negativos com o repatriamento de divisas, conforme ilustra a seguinte Tabela 13.

\footnotetext{
${ }^{5}$ Segundo dados da Conjuntura Econômica de novembro de 1998, o número de distribuidoras e corretoras de valores caiu de 374 e 285 em 1994 para 218 e 193 em 1998 representando variações de $-41,71 \%$ e $-32,28 \%$, respectivamente.

${ }^{6}$ PROER - Programa de Estímulo à Reestruturação e ao Fortalecimento do Sistema Financeiro Nacional e (*)PROES - Programa de incentivo à Redução do Setor Público Estadual na Atividade Bancária; a participação dos bancos estaduais nos créditos e depósitos passou, respectivamente, de 20,4 e 20,2 em junho de 1995 para 4,0 e 7,7 em dezembro de 1998 conforme dados do Sisbacen.

${ }^{7}$ O PROER custou, segundo estimativas do Banco Bozano Simonsen, cerca de R\$ 21 Bilhões, ou 3,8 \% do PIB (ALMEIDA, 2001). Já segundo estudo do Fundo Monetário Internacional, feito por Gerard Caprio e Daniela Kingebiel, em mais de 10 países a crise bancária gerou dispêndios superiores a $10 \%$ do PIB desses países (ALMEIDA, 1997).

${ }^{8}$ Segundo dados do Banco Central o número de bancos com controle acionário estrangeiro passou de 19 em julho de 1994 para 36 em dezembro de 1998.

${ }^{9}$ A privatização da Telebrás foi a maior do mundo tendo acontecido no exercício de 1998. Outras privatizações, como do setor energético, continuaram ocorrendo, além dos desdobramentos dos investimentos no setor de telecomunicações pela quebra do monopólio estatal e conseqüente divisão do mercado de telefonia.
} 
Tabela 13 - Acompanhamento dos investimentos estrangeiros em Bolsa (U\$ Milhões)

\begin{tabular}{c|c}
\hline & $\begin{array}{c}\text { Saldo Líquido de } \\
\text { Investimentos em Bolsa }\end{array}$ \\
\hline 1991 & 386 \\
\hline 1992 & 1314 \\
\hline 1993 & 5477 \\
\hline 1994 & 3754 \\
\hline 1995 & 528 \\
\hline 1996 & 3593 \\
\hline 1997 & 1615 \\
\hline 1998 & -2462 \\
\hline 1999 & 1100 \\
\hline 2000 & -1834 \\
\hline 2001 & -728 \\
\hline 2002 & -336 \\
\hline 2003 (até jul.) & 542 \\
\hline
\end{tabular}

Fonte: Banco Central.

Em relação ao sistema financeiro nacional e no período compreendido entre 1997 e 2001, verificase que participou, em média, com 5,92\% do valor adicionado bruto gerado em nossa economia, conforme a Tabela 14 mostrada a seguir. Essa participação é compatível com a estabilidade financeira que promoveu grande ajuste nesse percentual se comparado à épocas anteriores, em ambiente com alta inflação, em que a participação do setor era muito mais expressiva ${ }^{10}$.

\section{Tabela 14 - Valor adicionado pelo sistema financeiro}

\begin{tabular}{c|c} 
& $\begin{array}{c}\text { Valor adicionado } \\
\text { bruto/PIB (\%) }\end{array}$ \\
\hline 1997 & $6,15 \%$ \\
\hline 1998 & $6,21 \%$ \\
\hline 1999 & $5,98 \%$ \\
\hline 2000 & $5,10 \%$ \\
\hline 2001 & $6,20 \%$ \\
\hline Média & $5,92 \%$ \\
\hline
\end{tabular}

Fonte: IBGE.

Em linhas gerais, o sistema financeiro tem cumprido uma atuação razoável dentro de suas funções essenciais, ou seja, liquidação, gestão monetária, eficiência na alocação, proteção contra riscos e diminuição de custos para operações de fusões e aquisições (CYSNE, 1996).

Em relação à liquidação das operações, o Brasil ocupa posição de destaque devido aos investimentos realizados para a liquidação financeira das operações no ambiente inflacionário (CYSNE, 1997). A criação e implementação do Sistema de Pagamentos Brasileiro aumentou ainda mais a eficiência da gestão e do controle do risco sistêmico em nosso mercado financeiro.

Na questão da gestão monetária, verificou-se um aumento significativo da transparência da atuação do Banco Central. Foram marcantes o estabelecimento de metas de inflação como objetivo da política monetária e a administração do câmbio através de regime flutuante. Contudo, tendo em vista que o governo continua sendo o principal demandante de recursos do sistema financeiro, por vezes a atividade de política monetária pode ser entendida como instrumento para se conseguir baratear o custo de financiamento do déficit fiscal.

A questão referente à alocação de recursos por parte dos investidores no mercado financeiro nacional é, razoavelmente, atendida devido ao aumento de produtos financeiros e à melhor gestão desses recursos em vista da diminuição dos custos, ocorridos em decorrência do elevado aumento de escala conseguido por grandes conglomerados financeiros ${ }^{11}$.

Nosso mercado, no que tange aos ativos de renda variável, ainda deixa muito a desejar em termos de disponibilidade de ativos, principalmente de novas emissões de ações por parte das companhias abertas de modo a possibilitar o aumento dos investimentos, principalmente por parte dos investidores institucionais (ROCCA, 2001 e CVM ${ }^{12}, 1999$ a 2002). A esse respeito, pode-se ilustrar a observância desses reflexos nos dados da Tabela 15 que evidencia os volumes alocados em fundos de investimento existentes no nosso mercado financeiro.

\footnotetext{
${ }^{10}$ A participação das instituições financeiras era maior em períodos inflacionários devido à receita gerada pelas receitas que a inflação gerava a favor dessas instituições. Essa situação motivou o PROER e PROES, influenciou o estímulo à entrada de grandes instituições internacionais, assim como terminou por fazer desaparecerem $22 \%$ das instituições entre dezembro de 1994 e maio de 1999 (ANDIMA, 1999).

${ }^{11}$ Essa observação pode ser encontrada na referência Silva e Neto no artigo "Economia de escala nos bancos brasileiros após o Plano Real"

${ }^{12}$ CVM - Comissão de Valores Mobiliários.
} 
Tabela 15 - Estrutura comparativa dos investimentos em fundos no Brasil (U\$ Bilhões)

\begin{tabular}{c|c|cc}
\hline & FIF $\left(^{*}\right)$ & FITVM $\left(^{* *}\right)$ & $\begin{array}{l}\text { Fundos Mútuos de } \\
\text { Privatização - FGTS }\end{array}$ \\
\hline 2000 & 134,3 & 11,6 & 1,2 \\
\hline 2001 & 137,3 & 9,7 & 1,0 \\
\hline 2002 & 88,8 & 8,0 & 1,1 \\
\hline 2003 (até jul.) & 135,5 & 9,9 & 1,3 \\
\hline
\end{tabular}

Fonte: Comissão de valores Mobiliários.

( $^{*}$ Estão incluídos nos FIF os fundos de renda fixa, DI, Cambial, Livre, Multimercados com e sem renda variável e alavancagem de acordo com a nova denominação da ANBID.

$\left.{ }^{(*}\right)$ Fundos de Investimento em Títulos e Valores Mobiliários.

A gestão do risco em nossa economia e em nosso mercado financeiro melhorou significativamente em vista do aumento de magnitude das transações nos mercados futuros de juros, câmbio e mercadorias na Bolsa Mercantil e de Futuros e das operações de securitização de recebíveis.

A participação do mercado segurador ainda se mostra pequena no total de negócios realizados em nosso sistema financeiro. O campo do seguro foi o que talvez tenha experimentado a maior retração em termos de investimento externo, acompanhada de perto pela drástica diminuição de corretoras, distribuidoras e instituições de asset management, conforme dados da Comissão de Valores Mobiliários. Contudo, vale ressaltar o crescimento significativo dos planos de previdência complementar supervisionados pela Superintendência de Seguros Privados e a necessidade do crescimento desse mercado como forma de se melhorar a gestão dos riscos operacionais, de patrimônio e de crédito das empresas e instituições financeiras.

Observou-se, ainda, um incremento muito grande no número de operações de fusões e aquisições (mergers and aquisitions) de empresas nos primeiros anos de estabilização monetária (ALMEIDA, 1997), sendo que essa atividade se verificou complementar às aquisições de empresas nacionais por investidores estrangeiros ou em decorrência da quebra de monopólios no país. Porém, esse movimento não pode ser entendido como um decréscimo no custo de assessoria financeira.

No tocante ao mercado de capitais, observase, cada vez menos, a utilização de emissões de ações como forma de financiar as captações por parte das empresas abertas nacionais, conforme já mencionado anteriormente. Os principais instrumentos de captação de recursos têm sido as debêntures e depois as notas comerciais, conforme demonstra a Tabela 16 a seguir.

Tabela 16 - Emissões Primárias (Bilhões de Reais)

\begin{tabular}{l|c|c|c|c|c|c|c|c} 
& $\mathbf{1 9 9 5}$ & $\mathbf{1 9 9 6}$ & $\mathbf{1 9 9 7}$ & $\mathbf{1 9 9 8}$ & $\mathbf{1 9 9 9}$ & $\mathbf{2 0 0 0}$ & $\mathbf{2 0 0 1}$ & $\begin{array}{c}\mathbf{2 0 0 2} \\
\text { (até nov.) }\end{array}$ \\
Ações & 1,9 & 1,2 & 4,0 & 4,1 & 2,8 & 1,4 & 1,4 & 1,0 \\
\hline Debêntures & 6,8 & 7,5 & 6,4 & 6,5 & 6,6 & 7,7 & 15,1 & 8,0 \\
\hline Notas Comerciais & 1,1 & 0,5 & 5,1 & 12,9 & 8,0 & 7,6 & 5,3 & 3,9 \\
\hline Outras emissões & 0,5 & 1,7 & 1,9 & 4,0 & 0,5 & 1,7 & 0,9 & 1,0 \\
\hline Total & 10,3 & 10,9 & 17,4 & 27,5 & 17,9 & 18,4 & 22,7 & 13,9 \\
\hline
\end{tabular}

Fonte: Comissão de Valores Mobiliários.

No mercado secundário, presenciou-se uma grande subida do volume negociado em nossas Bolsas nos primeiros anos do programa de estabilização (até a crise cambial de 1998) e uma queda posterior conforme a seguinte Tabela $17^{13}$. Se forem comparados os dados do mercado brasileiro com os dados de

${ }^{13}$ Em Rocca, 2001, podem-se ver maiores explicações para os motivos desses acontecimentos. 
outros mercados emergentes e desenvolvidos, verse-à que temos um grande caminho pela frente, se pretender dinamizar o mercado de capitais como forma de financiamento das sociedades abertas (ROCCA, 2001). Para ilustrar-se essa comparação, mostram-se os dados nas Tabelas 18 e 19 a seguir:

Tabela 17 - Volume Negociado no Mercado Secundário (U\$ Bilhões)

\begin{tabular}{l|c|c|c|c|c} 
& $\mathbf{1 9 9 5}$ & $\mathbf{1 9 9 6}$ & $\mathbf{1 9 9 7}$ & $\mathbf{1 9 9 8}$ & $\mathbf{1 9 9 9}$ \\
Brasil & 79 & 112 & 203 & $\mathbf{1 4 6}$ & $\mathbf{3 4}$ \\
\hline México & 34 & 43 & 52 & 13148 & 18574 \\
\hline EUA & 5108 & 7121 & 829 & 1167 & 1377 \\
\hline U.K. & 510 & 578 & 170 & 137 & 733 \\
\hline Coréia & 185 & 177 & 453 & 699 & 744 \\
\hline Espanha & 60 & 250 & & &
\end{tabular}

Fonte: site da Federação Internacional das Bolsas de Valores.

Tabela 18 - Valor de Mercado das Companhias (U\$ Bilhões)

\begin{tabular}{|c|c|c|c|c|c|}
\hline & 1995 & 1996 & 1997 & 1998 & 1999 \\
\hline Brasil & 147 & 216 & 255 & 160 & 222 \\
\hline México & 90 & 106 & 156 & 92 & 15 \\
\hline EUA & 6857 & 8484 & 11308 & 13451 & 16630 \\
\hline U.K. & 1407 & 1740 & 1996 & 2374 & 2930 \\
\hline Coréia & 181 & 138 & 42 & 115 & 30 \\
\hline
\end{tabular}

Fonte: site da Federação Internacional das Bolsas de Valores.

Tabela 19 - Número de Companhias Listadas em Bolsa

\begin{tabular}{l|c|c|c|c|c} 
& $\mathbf{1 9 9 5}$ & $\mathbf{1 9 9 6}$ & $\mathbf{1 9 9 7}$ & $\mathbf{1 9 9 8}$ & $\mathbf{1 9 9 9}$ \\
Brasil & 543 & 551 & 536 & 527 & 194 \\
\hline México & 185 & 193 & 198 & 8450 & 778 \\
\hline EUA & 7671 & 8479 & 8851 & 2399 & 7651 \\
\hline U.K. & 2078 & 2433 & 2046 & 748 & 1945 \\
\hline Coréia & 721 & 760 & 776 & 484 & 725 \\
\hline Espanha & 362 & 357 & 384 & & 718 \\
\hline
\end{tabular}

Fonte: site da Federação Internacional das Bolsas de Valores.

A Tabela 20, mostrada a seguir, apresenta a evolução recente do volume médio diário negociado na Bovespa, o número de companhias listadas, o valor de mercado dessas companhias listadas e quanto esse valor representa percentualmente do PIB. Logo após, será apresentada a Tabela 21 com os volumes negociados na Bolsa Mercantil e de Futuros em igual período. 
Tabela 20 - Negócios na Bovespa

\begin{tabular}{c|c|c|c|c}
\hline & Média Diária (U\$ Milhões) & Cias. Listadas & Valor de Mercado (U\$ Bilhões) & Valor do Mercado/PIB(\%) \\
\hline 1995 & 327 & 543 & 147 & 20,9 \\
\hline 1996 & 466 & 550 & 216 & 28,0 \\
\hline 1997 & 867 & 536 & 255 & 31,6 \\
\hline 1998 & 701 & 527 & 160 & 20,4 \\
\hline 1999 & 369 & 478 & 228 & 43,0 \\
\hline 2000 & 422 & 459 & 225 & 38,0 \\
\hline 2001 & 265 & 428 & 185 & 36,8 \\
\hline 2002 (até nov.) & 201 & 403 & 115 & 22,9 \\
\hline
\end{tabular}

Fonte: Comissão de Valores Mobiliários.

Tabela 21 - Negócios na Bolsa Mercantil e de Futuros

\begin{tabular}{c|c}
\hline & Média Diária de Volume de Negócios (U\$ Bilhões) \\
\hline 1995 & 12,4 \\
\hline 1996 & 19,1 \\
\hline 1997 & 27,7 \\
\hline 1998 & 23,8 \\
\hline 2000 & 9,6 \\
\hline 2001 & 4,8 \\
\hline 2002 (até nov.) & 4,9 \\
\hline
\end{tabular}

Fonte: Bolsa Mercantil e de Futuros.

Verificam-se, no âmbito do mercado de capitais, algumas iniciativas importantes para seu recrudescimento, como são exemplos as adesões institucionais do Banco Nacional de Desenvolvimento Econômico e Social, da Superintendência de Seguros Privados, da Secretaria de Previdência Complementar, da Comissão de Valores Mobiliários, da Bovespa e de outras instituições ligadas ao mercado (Central de Liquidação de Títulos Privados, Associação Nacional das Instituições do Mercado Aberto, Associação Nacional dos Bancos de Investimento, Associação dos Profissionais de Investimentos do Mercado de Capitais, entre outras) em prol de dinamizar o aumento de participação dos investidores nos negócios envolvendo os ativos financeiros ${ }^{14}$.

A atuação do Banco Nacional de Desenvolvimento Econômico e Social seguirá no sentido de exigir que as empresas promovam a abertura de capital e a melhoria de suas práticas de governança corporativa, em contrapartida aos empréstimos que financiará. Da mesma forma a Superintendência de Seguros Privados e a Secretaria de Previdência Complementar, como instrumentos do Conselho Monetário Nacional, expediram normatizações que possibilitaram o aumento da participação dos investidores institucionais em companhias com boas práticas de governança corporativa ${ }^{15}$.

A atuação da Comissão de Valores Mobiliários, em conjunto com a reforma legal da Lei das Sociedades Anônimas e da Lei de criação da própria Autarquia, vem possibilitando a melhoria do aspecto regulatório do mercado de capitais (PUGA, 2001). Além disso, observa-se um processo de melhoria da fiscalização sobre os sistemas de intermediação de valores mobiliários e da divulgação do mercado de capitais através de sua área de orientação e

\footnotetext{
${ }^{14}$ Em Puga, 1999, pôde ser encontrada uma série de eventos ao longo do tempo que evidenciam o aumento da eficiência da atuação dos órgãos reguladores e da regulamentação do sistema financeiro como um todo. Em Andrezzo, 1999, p. 248 e 249, encontram-se resumidas as principais alterações ocorridas no mercado de capitais após o Plano Real.

${ }^{15}$ O BNDES criou o Programa de apoio às novas Sociedades Anônimas; foram expedidas as Resoluções CMN/SPC $\mathrm{n}^{\circ} 2829 / 2001$ possibilitando maiores investimentos de investidores institucionais em companhias com melhores práticas de governança e a resolução CMN/SUSEP $\mathrm{n}^{\circ} 3000 / 2002$ possibilitando incremento de investimentos por parte das seguradoras em empresas com melhores práticas de governança.
} 
educação de investidores, que atua em sentido análogo ao que atuava o Comitê de Divulgação do Mercado de Capitais (RELATÓRIO ANUAL DA COMISSÃO DE VALORES MOBILIÁRIOS, 2002).

Além disso, a definição de um Plano Diretor para o Mercado, a proposta de educação continuada dos profissionais ligados ao mercado de capitais, as novas práticas de governança corporativa, a criação do Instituto Brasileiro de Governança Corporativa, a criação da Associação Nacional de Investidores do Mercado de Capitais e a internacionalização de nossa economia apontam no sentido de valorizar a participação do mercado de capitais em nosso sistema financeiro.

\section{CONCLUSÕES}

Observa-se que muitos avanços ocorreram nos últimos anos sendo o principal deles a queda dos índices inflacionários para patamares menos desajustados do que aqueles com que a sociedade brasileira convivera durante as últimas décadas.

Verifica-se, também, que o setor governamental ainda apresenta um enorme déficit fiscal se incluídas as contas da previdência e do pagamento dos juros de suas dívidas interna e externa. Medidas que viabilizem 0 equacionamento das contas previdenciárias abrandariam diretamente as necessidades de financiamento do governo e indiretamente sinalizariam no sentido de se terem novas perspectivas para as demandas governamentais de recursos e com isso serem diminuídos os prêmios de risco atrelados à captação desses recursos.

Percebe-se que o modelo de endividamento adotado pelo governo nas últimas décadas causa ciclotomias que levam nossa economia a ter períodos de crescimento curtos e longos prazos de recessão e reajustamento. Assim sendo, um dos motivos das altas taxas de juros pagas pelo país é a necessidade de reformas urgentes que dinamizem nossa economia (ALMEIDA, 2001). As reformas tributária, política, do judiciário, da previdência, da legislação trabalhista entre outras são medidas urgentes para que o país possa galgar novos patamares de atuação no cenário mundial, principalmente aumentando sua inserção no comércio mundial e fazendo crescer seu produto.

Em relação ao mercado financeiro, perceberamse avanços na transparência das atividades do Banco Central, na eficiência da condução da política monetária em vista das metas de inflação a serem perseguidas e da política cambial, contudo, continuase a exigir uma autoridade monetária independente para a condução dessas atividades e da fiscalização das instituições financeiras de forma preventiva.

As instituições do mercado financeiro desempenham com eficiência a liquidação das operações e aumentaram o espectro de produtos que permitem maior facilidade para a alocação da poupança dos investidores, contudo ainda não desempenham com eficiência a gestão de riscos principalmente pelo pequeno tamanho de nosso mercado segurador em vista do seu potencial.

No tocante ao mercado de crédito, verifica-se que esse segue atrofiado em vista do desajuste de nossas taxas reais de juros e pela atuação do Estado ora como fornecedor de crédito, ora como demandante de recursos.

A respeito da crescente concentração das instituições financeiras, essa pode servir para repassar à sociedade uma diminuição de custos para a intermediação financeira em vista das economias de escala. Nesse sentido, deve-se incluir o aumento da participação de grandes instituições financeiras estrangeiras. Porém, ainda não se percebe uma atividade muito grande de fusões, aquisições, emissões de ações e reestruturações societárias em nosso mercado empresarial (que seriam benefícios decorrentes dessa economia), em parte devido aos elevados custos de consultoria e serviços financeiros (ROCCA, 2001).

Em resumo, verifica-se que ocorreram melhorias qualitativas muito grandes na gestão das atividades desenvolvidas em nosso mercado financeiro e que existe um processo ainda longo de ajustamento das contas públicas. Contudo, todo esse processo é plenamente compatível com uma economia em desenvolvimento como a nossa. 


\section{REFERÊNCIAS BIBLIOGRÁFICAS}

ALMEIDA, Ilton dos Santos. Avaliação e desempenho do sistema bancário brasileiro. 1997. 222 f. Dissertação de Mestrado. Fundação Getúlio Vargas, Rio de Janeiro, 1997.

ALMEIDA, Wagner Soares de. The recent evolution of the financial system: the brazilian case. The George Washington University, Institute of Brazilian Business and Public Managemnt Issues - IBI - 2000. Monografia.

ANDIMA. Relatório econômico - Sistema financeiro no Mercosul: uma análise comparativa. Rio de Janeiro. Dezembro, 1999.

ANDREZO, Andrea Fernandes, LIMA, Iran Siqueira. Mercado financeiro - aspectos históricos e conceituais. São Paulo: Pioneira, 1999

BANCO CENTRAL DO BRASIL. Site para localizações de séries temporais e dados estatísticos; Site da Comissão de Valores Mobiliários para localização de dados relacionados ao mercado de capitais brasileiro.

BANCO CENTRAL. Relatórios de avaliação da economia brasileira nos anos de 1995 até 2002.

BARROS, J. R. M. de; LOYOLA, Gustavo J. L; BOGDANSKI, J. Reestruturação do sistema financeiro no Brasil. Ministério da Fazenda - Secretaria de Política Econômica. Janeiro, 1998.

CINTRA, M. A. M. A montagem de um novo regime monetário financeiro nos Estados Unidos: 1982-94. São Paulo: FUNDAP, 1998.

COMISSÃO DE VALORES MOBILIÁRIOS. Relatórios anuais de 1999 a 2002.

CYSNE, R. P; Costa G. S. Reflexos do plano real sobre o sistema financeiro brasileiro. Ensaio econômico da EPGE $n^{\circ} 279$, junho de 1996.
DORNBUSCH, R; FISCHER, Stanley. Macroeconomia. $2^{a}$ ed., McGraw-Hill, 1991.

FEDERAÇÃO INTERNACIONAL DAS BOLSAS. Site para localização de dados relacionados ao mercado de capitais do exterior.

LAMEIRA, Valdir de Jesus Lameira. Mercado de capitais. $2^{a}$ ed., Rio de Janeiro: Forense Universitária, 2001.

LAMEIRA, Valdir de Jesus. A estrutura de capital das sociedades anônimas. Rio de Janeiro: Forense Universitária, 2001.

MALAN, Pedro S. Perspectivas para o desenvolvimento sustentado. Rio de Janeiro, XII Fórum Nacional. Representando o Brasil: futuro, presente e passado. Maio/2000, José Olympio Editora.

PINHEIRO, Juliano L. Mercado de capitais. São Paulo: Atlas, 2001.

PUGA, Fernando P. Sistema financeiro: Reestruturação recente, comparações internacionais e vulnerabilidade à crise cambial. Texto para discussão $n^{\circ} 68$. Março, 1999. Artigo disponibilizado no site do BNDES.

RESOLUÇÃO CMN/SPC No 2829/2001. Expedida pelo ConseIho Monetário Nacional e Secretaria de Previdência Complementar.

RESOLUÇÃO CMN/SUSEP Nº 3000/2002. Expedida pelo Conselho Monetário Nacional e Superintendência de seguros Privados.

ROCCA, Carlos Antônio. Soluções para o desenvolvimento do mercado de capitais brasileiro. Rio de Janeiro: José Olympio, 2001.

SILVA, T. L. de; NETO, P. de M. J. Economia de escala nos bancos brasileiros após o Plano Real. Fortaleza. Texto para discussão $n^{\circ}$ 227. Pós-graduação em Economia da Universidade Federal do Ceará. Julho, 2001.

NOTA:

Endereço do autor:

PUC - Seção de Pós-Graduação

Rua Marquês de São Vicente, 225 - Gávea

Rio de Janeiro - RJ

22453-900 